\title{
Assessing the Perceptions and Practice of Self-Medication among Bangladeshi Undergraduate Pharmacy Students
}

\author{
Md. Omar Reza Seam ${ }^{1}$, Rita Bhatta ${ }^{1}$, Bijoy Laxmi Saha ${ }^{1}$, Abhijit Das ${ }^{1}$ (D), Md. Monir Hossain ${ }^{1}$, \\ S. M. Naim Uddin ${ }^{2}$, Palash Karmakar ${ }^{1, *}$, M. Shahabuddin Kabir Choudhuri ${ }^{3}$ \\ and Mohammad Mafruhi Sattar ${ }^{3}$ \\ 1 Department of Pharmacy, Noakhali Science and Technology University, Sonapur, Noakhali 3814, Bangladesh; \\ omarrezaseam@gmail.com (M.O.R.S.); phar_rita@yahoo.com (R.B.); bijoylaxmi.saha@yahoo.com (B.L.S.); \\ abhijitdas@nstu.edu.bd (A.D.); monirjupharmacy@gmail.com (M.M.H.) \\ 2 Department of Pharmacy, University of Chittagong, Chittagong 4331, Bangladesh; pharma.naim@yahoo.com \\ 3 Department of Pharmacy, Jahangirnagar University, Savar, Dhaka 1342, Bangladesh; \\ mskchoudhuri@juniv.edu (M.S.K.C.); mafruhi1968@yahoo.com (M.M.S.) \\ * Correspondence: pk@nstu.edu.bd; Tel.: +88-01717-036968
}

Received: 10 November 2017; Accepted: 1 January 2018; Published: 15 January 2018

\begin{abstract}
Objectives: To evaluate the perceptions and extent of practicing self-medication among undergraduate pharmacy students. Methods: This cross-sectional, questionnaire-based study was conducted over a six month period (January to June 2016) among undergraduate pharmacy students in five reputable public universities of Bangladesh. It involved face-to-face interviews regarding self-medication of 250 respondents selected by simple random sampling. Results: Self-medication was reported by $88.0 \%$ of students. Antipyretics (58.40\%) were mostly preferred for the treatment of fever and headaches. The major cause for self-medication was minor illness $(59.60 \%, p=0.73)$ while previous prescriptions were the main source of knowledge as well as the major factor $(52.80 \%, p=0.94)$ dominating the self-medication practice. The results also demonstrated $88.80 \%$ of students had previous knowledge on self-medication and $83.60 \%$ of students always checked the information on the label; mainly the expiry date before use $(85.60 \%)$. A significant $(p<0.05)$ portion of the students $(51 \%$ male and $43 \%$ female) perceived it was an acceptable practice as they considered self-medication to be a segment of self-care. Furthermore, students demonstrated differences in their response level towards the adverse effect of drugs, the health hazard by a higher dose of drug, a physician's help in case of side effects, taking medicine without proper knowledge, and stopping selling medicine without prescription. Conclusions: Self-medication was commonly used among pharmacy students primarily for minor illnesses using over-the-counter medications. Although it is an inevitable practice for them it should be considered an important public health problem as this practice may increase the misuse or irrational use of medicines.
\end{abstract}

Keywords: self-medication; pharmacy students; awareness; perception; Bangladesh

\section{Introduction}

Self-medication is a human trait in which an individual (or a member of the individuals' family) selects and uses medicines or any other substances for the treatment of self-recognized or self-diagnosed physical or psychological ailments [1]. Conventionally it has been described as the intake of drugs, herbs or other home remedies on an individual's own persuasion or taking the advice of another person without consulting a physician [2,3]. Thus it forms an integral part of patients' self-care which in fact is the first choice and is one of the most crucial tools when an 
individual encounters common health problems that do not require a doctor's visit $[4,5]$. Due to insufficient medical facilities, the free accessibility of over-the-counter (OTC) drugs in the local market and the impoverished national drug regulatory policy, it is now becoming a very common occurrence in numerous countries of the world. Other reasons for self-medication are the shortage of time to visit a physician, inability to get a quick appointment, mild illness, long distance of hospitals and clinics from home, and finally unaffordable doctor's fees. Moreover, extraction of much information from online sources, magazines or periodicals makes people courageous about treating their own illness [6]. However, people are endangering their lives by practicing self-medication as it can lead to habituation, lethal allergic reactions, under dosage of medication which may not alleviate the symptom, and also over dosage that can cause collateral injury to different organs [7].

The substances which are most extensively self-medicated are OTC drugs and dietary supplements. Besides analgesics, antimalarials, antibiotics, and cold syrups are intermittently used for self-administration [8]. Sometimes some psychoactive drugs like recreational drugs, alcohol, and comfort foods are self-medicated to alleviate the symptoms of mental distress, stress, and anxiety [9]. The practice of self-medication has become very familiar throughout the world [10-13] with a high prevalence rate in developing countries $[14,15]$. Some studies have found that the amplitude of self-prescribing rate with antibiotics in Asia is 4-7.5\% which is higher that of 3\% in northern Europe [16]. Although self-medication, when practiced precisely can save time and is also cost effective to the patients where professional care is relatively expensive and not readily available, there are several critical health hazard issues that should be considered before endorsing the potential benefits of self-medication $[7,17,18]$. Sometimes it may lead to wastage of resources, boost up resistance to pathogens, and cause severe health problems, including adverse drug reaction, addiction, and ultimately death [7].

There are no examples of data relating health hazards and health care utilization including the practice of self-medication among young adults, but it is expected that they are highly motivated towards self-administration of drugs by the internet and media [19]. A study carried out by the university students of Karachi, Pakistan demonstrated that the propensity of self-prescribing of medications among medical students was $77.7 \%$, and was $83.3 \%$ for non-medical students [20]. So the study on self-practice of medications among university pharmacy undergraduates is imperative as they are that segment of the population who are well educated and have access to all the information regarding their health. Moreover study on the tendency of self-medication practice among pharmacy undergraduates is essential as they are the oncoming drug prescribers and health educationalist [5].

Over-the-counter (OTC) drugs are the only drugs which can be self-prescribed and sold in convenience stores, grocery stores, and health shops without prescription as they are less hazardous [21]. In Bangladesh paracetamol, ORS saline, metronidazole, ranitidine, omeprazole, aspirin, and diaclofenac sodium etc. are accepted to be sold as OTC drugs. However, due to immoral drug sellers and improper regulation, $90 \%$ of stocked drugs are sold without any prescription and therefore the phenomenon of self-medication is a common topic in our country [21]. Besides there have been very confined researches conducted regarding the impact of self-medication practice among university pharmacy undergraduates [15].

Considering all this evidence, this research work focuses on assessing the perceptions about self-medication practice among the pharmacy students of Bangladesh. The study also compares the attitudes toward and the extent of practicing self-care between male and female students, as well as the year in pharmacy school.

\section{Methods}

\subsection{Study Design}

This population-based cross-sectional study was carried out to investigate the knowledge, attitudes and practice of self-medication among the undergraduate pharmacy students of Bangladesh from January to June, 2016. The study was conducted by using both qualitative and quantitative data. 


\subsection{Study Area}

To conduct the study, the pharmacy department of five public universities of Bangladesh namely Dhaka University, Jahangirnagar University, Chittagong University, Comilla University, and Noakhali Science and Technology University were chosen as the study area. The above mentioned universities were chosen by the field investigators based on the availability and accessibility of the participants. Time and distance were also the key factors for the selection of the study areas.

\subsection{Study Participants}

The study included 250 undergraduate students (131 male and 119 female) enrolled in a Bachelor of Pharmacy program who understood English, aged between 18-25 years and were permanent residents of Bangladesh, with different socioeconomic backgrounds from five different public universities. Both residential and nonresidential students were selected randomly, i.e., we did not consider whether the students were resident or non-resident in different halls of the university. Before data collection each and every participant was clearly informed about the purpose of the study and a written consent was taken from each of the respondents.

\subsection{Participants and Eligibility Criteria}

This study included only those respondents who were easily available for data collection and interested to provide information willingly. Those who did not feel comfortable to give information were excluded from the study.

\subsection{Sampling and Sample Size}

A simple random sampling technique was used for the selection of study participants. The sample size was calculated assuming that $50 \%$ of the undergraduate pharmacy students had a tendency of self-medication practice with 5\% margin of error and $95 \%$ confidence interval. The sample size was calculated to be 232. However, to ensure more representative data, we selected a larger sample size of 250 for this study.

\subsection{Data Collection}

The procedure of data collection was segmented into three steps. The first step was to fill out the questionnaire including socio-demographic information by the study subjects. The second step was to discuss the study protocol, and the final step was to cross-check the questionnaires filled by the respondents. The questionnaire was adopted from a formerly published study which was developed, standardized, and previously used by Kumar et al. [4] for undergraduate pharmacy students. The questionnaire was divided into four segments and consisted of 16 close-ended and 11 open-ended questions. Section 1 contained questions related to socio-demographic information of the respondents. Section 2 included questions about the practice of self-medication by the respondents. Section 3 was concerned with the knowledge and awareness related questions of the respondents while Section 4 was on questions related to the perception of the respondents regarding self-medication practice.

The questionnaire was distributed to the selected student together with a written consent form that explained the purpose of the research and assured them of their confidentiality. The interviews lasted for $15 \mathrm{~min}$ and included a range of questions about self-medication along with an explanation about self-medication, its main principles, as well as evidence based and practical demonstration. The questionnaire was constructed in English and translated to Bengali by the interviewers to make the questions easily understandable to the participants during the interview. They were asked to complete the questionnaire immediately. The authors were present on hand to answer questions or clarify any doubts that they might have. 


\subsection{Statistical Analysis}

Data analyses were conducted using SPSS software version 20.0 (SPSS Inc., Chicago, IL, USA). Descriptive statistics was used for the calculation of proportions. The Chi-square test was performed to measure the association between the demographic characteristics and responses to understanding, perceptions and self-use of medication. The $p$ values were calculated by the Chi-square test. An alpha level of 0.05 or less was considered significant. The Microsoft excel program was used for data analysis and for chart, graph, and diagram preparation.

\section{Results}

\subsection{Demographic Characteristics}

Table 1 shows that $52.40 \%$ of the students were male while female students comprised $47.60 \%$. Among all the pharmacy students $26 \%$ was from the 1 st year, $26.00 \%$ from the 2 nd year, $26.00 \%$ from the 3rd year, and $22.00 \%$ from the 4 th year. The lowest number of students was in the age group $<18$ years with a percentage of $5.20 \%$ while the highest number of students was in the $21-25$ years age group with a percentage of $63.60 \%$. Another $31.20 \%$ of students was in the age group $18-20$ years. Among the respondents $80.40 \%$ of respondents was from an urban area and $19.60 \%$ was from a rural area.

Table 1. Demographic characteristics of respondents.

\begin{tabular}{cccc}
\hline Item & Sub Group & Number (n) & Percentage (\%) \\
\hline \multirow{2}{*}{ Sex } & Male & 131 & 52 \\
& Female & 119 & 48 \\
\hline \multirow{4}{*}{ Year of study } & 1st year & 65 & 26 \\
& 2nd year & 65 & 26 \\
& 3rd year & 65 & 26 \\
& 4th year & 55 & 22 \\
\hline \multirow{2}{*}{ Age group } & $<18$ year & 13 & 5 \\
& 18-20 year & 78 & 31 \\
& 21-25 year & 159 & 64 \\
\hline \multirow{2}{*}{ Area of residence } & Urban & 201 & 80 \\
& Rural & 49 & 20 \\
\hline
\end{tabular}

\subsection{Practice of Self-Medication}

Table 2 describes the practice of self-medication by pharmacy students (from 1st year to 4th year) from five reputable public universities of Bangladesh. From the table we get a clear scenario that the majority of students reported practicing self-medication (88.0\%). The practice of self-medication among both male and female students $(45.20 \%$ and $42.80 \%$ respectively) was almost similar with no significant difference $(p>0.05)$.

Table 2. Practice of self-medication of the respondents.

\begin{tabular}{ccccccccc}
\hline \multirow{2}{*}{ Item } & \multirow{2}{*}{ Response } & \multicolumn{2}{c}{ Male } & \multicolumn{2}{c}{ Female } & Total (\%) & $p$-Value \\
\cline { 3 - 8 } & & $\mathbf{n}$ & $\mathbf{0}$ & $\mathbf{n}$ & $\mathbf{\%}$ & & \\
\hline \multirow{2}{*}{ Practice of self-medication } & Yes & 113 & 45.20 & 107 & 42.80 & $220(88.0)$ & 0.44 \\
& No & 18 & 7.20 & 12 & 4.80 & $30(12.0)$ & \\
\hline
\end{tabular}

$\mathrm{n}$ indicates the number of respondents. $p$ value was determined using Chi-square Test. $p<0.05$ was considered significant when compared between male and female groups.

\subsection{Purpose of Self-Medication Practice}

Table 3 demonstrates that the use of self-medication practice for different complications differed insignificantly $(p>0.05)$ between male and female students. It can also be seen from the table that 
students used self-medication for headache (71.20\%); cough, cold/flu (61.20\%); diarrhea (47.60\%); pain $(42.80 \%)$; stomach ache (32.80\%); vomiting (32.00\%); rash/allergies $(23.60 \%)$, and skin problems $(16.40 \%)$ respectively. Here the percentage of using self-medication for fever was highest and the value was least for ear problems.

Table 3. Purpose of practicing self-medication of the respondents.

\begin{tabular}{|c|c|c|c|c|c|c|c|}
\hline \multirow{2}{*}{ Items } & \multicolumn{2}{|c|}{ Male } & \multicolumn{2}{|c|}{ Female } & \multirow{2}{*}{ Total (\%) } & \multirow{2}{*}{$x^{2}$ Value } & \multirow{2}{*}{$p$ Value } \\
\hline & $\mathbf{n}$ & $\%$ & $\mathbf{n}$ & $\%$ & & & \\
\hline \multicolumn{8}{|l|}{ Indications for Using Self-Medication } \\
\hline Headache & 89 & 35.60 & 89 & 35.60 & $178(71.20)$ & 1.59 & 0.66 \\
\hline Cough, Cold/Flu & 75 & 30.00 & 78 & 31.20 & $153(61.20)$ & 1.41 & 0.72 \\
\hline Fever & 98 & 39.20 & 93 & 37.20 & $191(76.40)$ & 1.62 & 0.67 \\
\hline Stomach ache & 34 & 13.60 & 48 & 19.20 & $82(32.80)$ & 1.88 & 0.62 \\
\hline Diarrhea & 66 & 26.40 & 53 & 21.20 & $119(47.60)$ & 2.76 & 0.43 \\
\hline Menstrual Symptoms & 0 & 0 & 12 & 4.80 & $12(4.80)$ & - & - \\
\hline Rash/Allergies & 26 & 10.40 & 33 & 13.20 & $59(23.60)$ & 2.46 & 0.49 \\
\hline Anxiety/Depression & 7 & 2.80 & 10 & 4.00 & $17(6.80)$ & 3.29 & 0.45 \\
\hline Ear Problems & 3 & 1.20 & 2 & 0.80 & $5(2.00)$ & 2.10 & 1.00 \\
\hline Vomiting & 37 & 14.80 & 43 & 17.20 & $80(32.00)$ & 4.54 & 0.21 \\
\hline Eye infections & 7 & 2.80 & 9 & 3.60 & $16(6.40)$ & 3.81 & 0.13 \\
\hline Skin problems & 27 & 10.80 & 14 & 5.60 & $41(16.40)$ & 1.02 & 0.83 \\
\hline Tooth ache & 17 & 6.80 & 11 & 4.40 & $28(11.20)$ & 0.41 & 1.00 \\
\hline Insomnia & 3 & 1.20 & 3 & 1.20 & $6(2.40)$ & 3.13 & 1.00 \\
\hline Pain & 51 & 20.40 & 56 & 22.40 & $107(42.80)$ & 5.20 & 0.15 \\
\hline \multicolumn{8}{|l|}{ Reason for Self-Medication } \\
\hline Minor illness & 72 & 28.80 & 77 & 30.80 & $149(59.60)$ & 1.35 & 0.73 \\
\hline Sufficient pharmacological knowledge & 27 & 10.80 & 21 & 8.40 & $48(19.20)$ & 1.56 & 0.74 \\
\hline Quick relief & 40 & 16.00 & 37 & 14.80 & $77(30.80)$ & 2.17 & 0.56 \\
\hline Lack of time to consult doctor & 35 & 14.00 & 29 & 11.60 & $64(25.60)$ & 3.99 & 0.26 \\
\hline Cost effectiveness & 22 & 8.80 & 10 & 4.00 & $32(12.80)$ & 1.28 & 0.86 \\
\hline Easy availability of medicine & 52 & 20.80 & 36 & 14.40 & $88(35.20)$ & 3.02 & 0.39 \\
\hline Emergency use & 34 & 13.60 & 46 & 18.40 & $80(32.00)$ & 2.19 & 0.53 \\
\hline \multicolumn{8}{|l|}{ Type of Self-Prescribed Medicine } \\
\hline Analgesics & 63 & 25.20 & 60 & 24.00 & $123(49.20)$ & 0.60 & 0.93 \\
\hline Antipyretics & 44 & 17.60 & 53 & 21.20 & $146(58.40)$ & 2.44 & 0.48 \\
\hline Antidiarrheals & 48 & 19.20 & 50 & 20.00 & $98(39.20)$ & 2.64 & 0.44 \\
\hline Antiemetics & 13 & 5.20 & 20 & 8.00 & $33(13.20)$ & 4.30 & 0.22 \\
\hline Antibiotics & 27 & 10.80 & 12 & 4.80 & $39(15.60)$ & 1.73 & 0.66 \\
\hline Antacids & 71 & 28.40 & 75 & 30.00 & $97(38.80)$ & 3.58 & 0.31 \\
\hline Sedatives & 11 & 4.40 & 12 & 4.80 & $23(9.20)$ & 4.38 & 0.20 \\
\hline Anti-allergic & 36 & 14.40 & 37 & 14.80 & $73(29.20)$ & 3.15 & 0.38 \\
\hline Vitamins & 40 & 16.00 & 39 & 15.60 & $79(31.60)$ & 7.62 & 0.05 \\
\hline Ophthalmic preparations & 1 & 0.40 & 3 & 1.20 & $4(1.60)$ & - & 1.00 \\
\hline Cosmetic products & 21 & 8.40 & 34 & 13.60 & $55(22.00)$ & 1.72 & 0.64 \\
\hline
\end{tabular}

Data is represented both as number and percentage (\%). $\mathrm{n}$ indicates the number of respondents. $p$ values from Chi-square or Fisher Exact tests for comparisons between male and female groups.

The purpose of self-practicing of medications by the students was categorized into seven broad categories (Table 3). The majority of the students (59.60\%) used self-medication because they thought that they did not need to see a doctor for a minor illness. Easy availability of medicines (32.20\%) and emergency use (32.00\%) were the secondary reasons for practicing self-medication. Meanwhile quick relief (30.80\%), lack of time to consult doctor (25.60\%), sufficient pharmacological knowledge (19.20\%), and cost effectiveness (12.80\%) were other reasons behind self-medication of drugs. The table shows some high values on the purpose of using self-medication, but none of the values was significant $(p>0.05)$.

Different categories of medicine which were self-medicated by the students for the treatment of ailments are listed in Table 3. From the table it is clear that the use of different classes of drugs showed no difference in use between males and females. Among the drugs the rate of antipyretic consumption was highest (58.40\%) by the students whereas analgesics (49.20\%); anti-diarrheal (39.20\%); 
antacid (38.80\%); vitamins (31.60\%); anti-allergic (29.20\%); cosmetics $(22.00 \%)$, and anti-diabetics $(15.60 \%)$ were also used by them. It was found that among different types of drugs students used ophthalmic preparations the least with a percentage of $1.60 \%$.

\subsection{Sources of Information on Self-Medication Practice}

Figure 1 represents the pharmacy students' (1st to 4th year) source of information on the medications self-prescribed by them. From the diagram we get a clear picture that the majority of the male and female students considered an old prescription for common illness (56\% and 58\% respectively) and academic knowledge ( $62 \%$ and $55 \%$ respectively) as their primary sources of information on self-medicated drugs. It was an interesting finding that male students gathered information about medicines from friends $(32 \%)$, internet $(35 \%)$, and advertisement $(30 \%)$ and this rate was higher in comparison to female students.

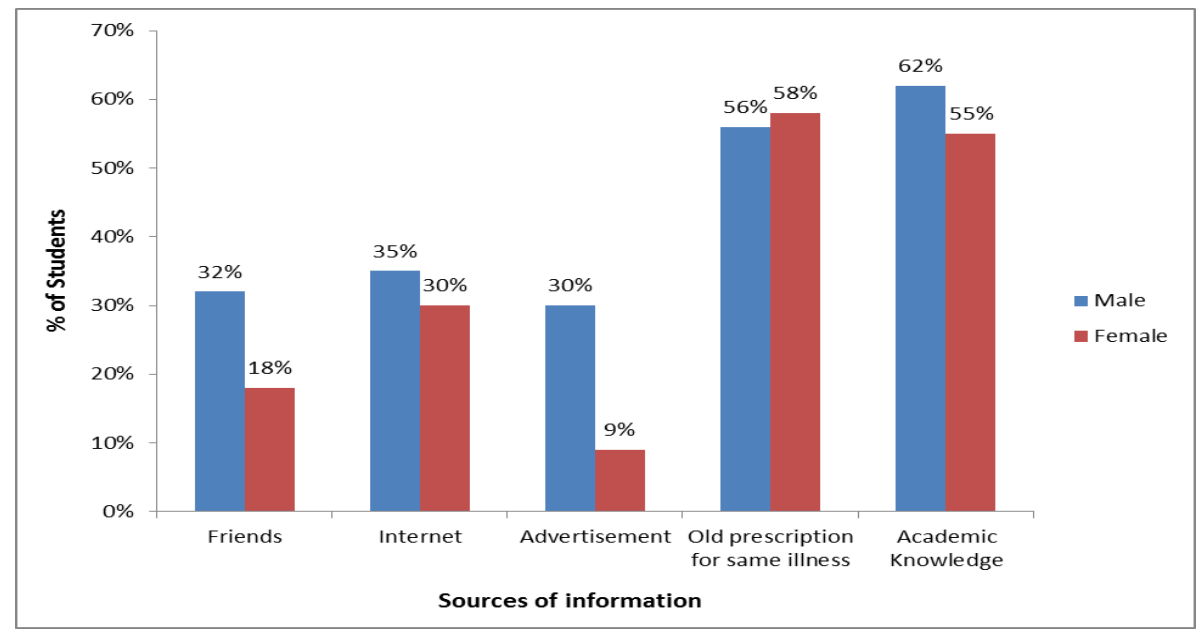

Figure 1. Sources of information on self-medicated drugs. Data is represented as percentage (\%) for the two groups.

\subsection{Factors Influencing Self-Medication Practice}

Table 4 represents a pharmacy student's opinion on the factors (predefined categories from the survey) which influence the practice of self-medication. A major portion of the students $(52.80 \%)$ said that they had self-prescribed a drug based on the previous doctor's prescription for the same disease. Another $50.80 \%$ students had previous experience of practicing self-medication while the opinions of family members $(45.20 \%)$ and of friends $(15.20 \%)$ were also influential factors for self-medication practice by the students. Advertisement (6.00\%) and recommendation by local people $(5.60 \%)$ were the least influential factors for self-prescription of medications.

Table 4. Influencing factors for the selection of medications for self-practice by the respondents.

\begin{tabular}{cccccccc}
\hline \multirow{2}{*}{ Factors } & \multicolumn{2}{c}{ Male } & \multicolumn{2}{c}{ Female } & \multirow{2}{*}{ Total (\%) } & \multirow{2}{*}{$x^{\mathbf{2}}$ Value } & \multirow{2}{*}{$\boldsymbol{*}$ Value } \\
\cline { 2 - 5 } & $\mathbf{n}$ & $\mathbf{\%}$ & $\mathbf{n}$ & $\mathbf{\%}$ & & & \\
\hline Opinion of family members & 52 & 20.80 & 61 & 24.40 & $113(45.20)$ & 1.74 & 0.63 \\
Opinion of friends & 27 & 10.80 & 11 & 4.40 & $38(15.20)$ & 1.62 & 0.65 \\
Recommendation by local people & 10 & 4.00 & 4 & 1.60 & $14(5.60)$ & 1.14 & 0.57 \\
Previous doctor's prescription & 58 & 23.20 & 74 & 29.60 & $132(52.80)$ & 0.40 & 0.94 \\
Own experience & 75 & 30.00 & 52 & 20.80 & $127(50.80)$ & 9.08 & $0.03 *$ \\
Advertisement & 12 & 4.80 & 3 & 1.20 & $15(6.00)$ & 1.63 & 0.44 \\
\hline
\end{tabular}

$\mathrm{n}$ indicates the number of respondents. $p$ value was determined using Chi-square Test. ${ }^{*} p<0.05$ was considered significant when compared between male and female groups. 


\subsection{Knowledge on Self-Medication Practice}

Table 5 is concerned with the information relating to pharmacy students' perceived knowledge on self-medication practice. The table illustrates that most of the students who had self-prescribed medication for different diseases knew about self-medication $(88.80 \%)$ previously. Among the students $83.6 \%$ had a tendency to check the package insert while $85.6 \%$ students had a sound attitude towards checking the expiry date of the drug before using it. Furthermore $67.6 \%$ students had concerns about the importance of completing the course of the drug. All the results differed significantly $(p<0.05)$ when compared between male and female students.

Table 5. Knowledge of the students on self-medication.

\begin{tabular}{|c|c|c|c|c|c|c|c|}
\hline \multirow{2}{*}{ Modality } & \multicolumn{2}{|c|}{ Male } & \multicolumn{2}{|c|}{ Female } & \multirow{2}{*}{ Total (\%) } & \multirow{2}{*}{$x^{2}$ Value } & \multirow{2}{*}{$p$ Value } \\
\hline & $\mathbf{n}$ & $\%$ & $\mathbf{n}$ & $\%$ & & & \\
\hline Idea about self-medication & 130 & 52.00 & 92 & 36.80 & $222(88.80)$ & 8.84 & $0.03 *$ \\
\hline $\begin{array}{l}\text { Knowledge about dose completion of } \\
\text { self-prescribed medications }\end{array}$ & 90 & 36.00 & 79 & 31.60 & $169(67.60)$ & 14.16 & $0.00 *$ \\
\hline Checking of the insert & 120 & 48.00 & 89 & 35.60 & $209(83.60)$ & 7.54 & $0.03 *$ \\
\hline Checking of the expiry date before use & 110 & 44.00 & 104 & 41.60 & $214(85.60)$ & 8.17 & $0.04 *$ \\
\hline
\end{tabular}

$\mathrm{n}$ indicates the number of respondents. $p$ value was determined using Chi-square Test. ${ }^{*} p<0.05$ was considered as significant male and female groups.

\subsection{Attitude towards Self-Medication}

Figure 2 represents the pharmacy students' (1st to 4th year) approach on self-prescription of medication for self-healthcare. From the figure it is clear that the students' concept about self-medication was classified into three categories namely good practice, acceptable practice, and not acceptable practice. Both male (51\%) and female (43\%) considered self-medication an acceptable practice while another $17 \%$ male and 13\% female students considered self-practice of medication was good. Moreover the diagram also shows that $32 \%$ male and $44 \%$ female students thought self-medication was not an acceptable practice.

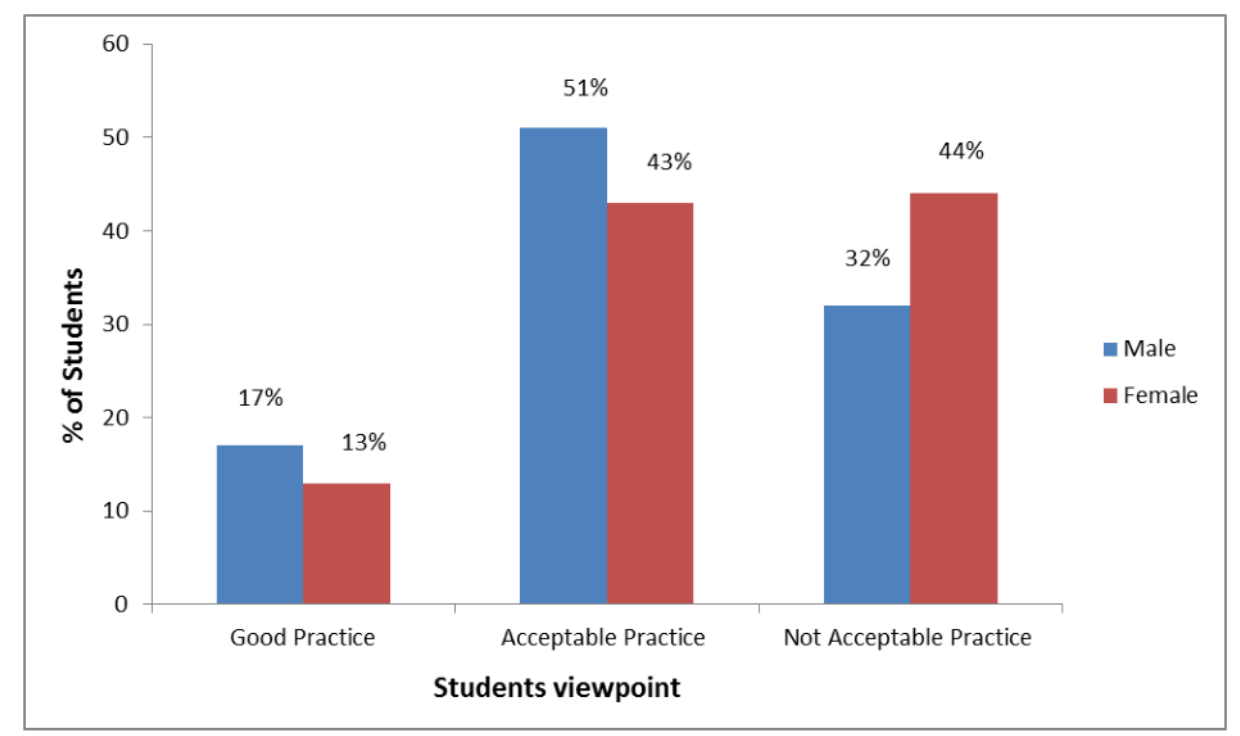

Figure 2. Attitude of the students towards self-medication. Data is represented as percentage (\%) for the two groups. 
Table 6 represents the students' attitudes on self-medication among 1st to 4th year pharmacy students of five reputed public universities. The answer level is given as "yes" and "no". The majority of students had a positive attitude on self-medication. A very negligible number of students had a negative attitude.

Table 6. Attitude of the students towards Self-medication.

\begin{tabular}{|c|c|c|c|c|}
\hline Modality & Year of Study & Yes/No (n) & $x^{2}$ Value & $p$ Value \\
\hline \multirow{4}{*}{ Part of self-care } & 1 st & $44 / 21$ & \multirow{4}{*}{3.27} & \multirow{4}{*}{0.12} \\
\hline & 2nd & $47 / 19$ & & \\
\hline & 3 rd & $47 / 19$ & & \\
\hline & 4 th & $45 / 10$ & & \\
\hline \multirow{4}{*}{$\begin{array}{l}\text { Advice of self-medication to your family } \\
\text { and friends }\end{array}$} & 1 st & $29 / 36$ & \multirow{4}{*}{0.50} & \multirow{4}{*}{0.98} \\
\hline & 2nd & $27 / 38$ & & \\
\hline & $3 r d$ & $26 / 39$ & & \\
\hline & 4 th & $25 / 30$ & & \\
\hline \multirow{4}{*}{ Idea about which drugs have side effects } & 1 st & $37 / 28$ & \multirow{4}{*}{6.35} & \multirow{4}{*}{0.22} \\
\hline & 2nd & $49 / 16$ & & \\
\hline & $3 r d$ & $48 / 17$ & & \\
\hline & 4 th & $37 / 18$ & & \\
\hline \multirow{4}{*}{$\begin{array}{l}\text { Concern that increasing drug dose can be } \\
\text { health hazardous }\end{array}$} & 1 st & $45 / 20$ & \multirow{4}{*}{12.80} & \multirow{4}{*}{$0.00 *$} \\
\hline & 2nd & $56 / 9$ & & \\
\hline & $3 r d$ & $59 / 6$ & & \\
\hline & 4 th & $48 / 7$ & & \\
\hline \multirow{4}{*}{$\begin{array}{l}\text { In the case of side effects a physicians } \\
\text { help must be needed }\end{array}$} & 1 st & $59 / 6$ & \multirow{4}{*}{3.29} & \multirow{4}{*}{0.66} \\
\hline & 2nd & $63 / 2$ & & \\
\hline & $3 r d$ & $61 / 4$ & & \\
\hline & 4 th & $49 / 6$ & & \\
\hline \multirow{4}{*}{$\begin{array}{l}\text { Mild medical problems do not need } \\
\text { drug treatment }\end{array}$} & 1 st & $21 / 44$ & \multirow{4}{*}{9.25} & \multirow{4}{*}{$0.02 *$} \\
\hline & 2nd & $29 / 36$ & & \\
\hline & $3 r d$ & $24 / 41$ & & \\
\hline & 4 th & $32 / 23$ & & \\
\hline \multirow{4}{*}{ Physicians can be overlooked } & 1 st & $43 / 22$ & \multirow{4}{*}{11.26} & \multirow{4}{*}{$0.00 *$} \\
\hline & 2nd & $40 / 25$ & & \\
\hline & $3 r d$ & $40 / 25$ & & \\
\hline & 4th & $21 / 34$ & & \\
\hline \multirow{4}{*}{$\begin{array}{l}\text { Taking without proper knowledge } \\
\text { is harmful }\end{array}$} & $1 \mathrm{st}$ & $54 / 11$ & \multirow{4}{*}{4.09} & \multirow{4}{*}{0.16} \\
\hline & 2nd & $60 / 5$ & & \\
\hline & $3 r d$ & $60 / 5$ & & \\
\hline & 4th & $50 / 5$ & & \\
\hline \multirow{4}{*}{$\begin{array}{l}\text { Stopping selling medicine } \\
\text { without prescription }\end{array}$} & 1 st & $56 / 9$ & \multirow{4}{*}{6.01} & \multirow{4}{*}{$0.03 *$} \\
\hline & 2nd & $56 / 9$ & & \\
\hline & $3 r d$ & $58 / 7$ & & \\
\hline & 4th & $54 / 1$ & & \\
\hline
\end{tabular}

$\mathrm{n}$ indicates the number of respondents. $p$ value was determined using Chi-square Test. ${ }^{*} p<0.05$ was considered significant for male and female groups.

The tabulated results show differences in response level of the students to some survey items such as self-medication is a part of self-care; the idea about drugs side effects; health hazard on increased dose of a drug; physician's help in case of side effects; taking medicine without proper knowledge, and stopping selling medicine without prescription. The observed answers were significant $(p<0.05)$ in the case of concern about the impact of increased dose of drug, for no need of drug treatment in mild medical cases, for overlooking physicians and not selling drugs without prescription, while for other modalities the results were not significant $(p>0.05)$.

\section{Discussion}

People have always been very cautious about their personal health status and for this they have used self-medication, a feature of healthcare, from ancient times. Although self-medication has 
many pros and cons it depends on who uses it and how it is used for self-treatment [4]. We focused on pharmacy students because they have adequate knowledge of medicine in theory and are more cautious about the safety of drugs which is lacking in other student groups or in the general population. Thus a pharmacy student's view on the self-medication practice can be considered as a major factor to judge the characteristics of their future prescription pattern.

Students of Bangladesh frequently use self-medication and gender difference has not been shown to have any influence on the practice of self-medication. The reason behind insignificant gender differences in the overall exercise of self-medication may be the study format that allowed the respondents to select drugs by themselves [5]. In our study we found that about $88.0 \%$ of the students self-practice different types of medication. A similar type of study was conducted by Kumar et al. [4] in coastal south India and signified that the amplitude of self-medication practice was $78.90 \%$ among medical students. Other similar studies also demonstrated the prevalence rate of self-medication ranged between $57.1 \%$ and $92 \%$ among the medicals students in India [22]. Several research works carried out in other developing countries revealed that the prevalence of self-medication was $38.5 \%$ and $43.2 \%$ among medical, pharmacy, and health science students in Ethiopia [22,23], 51\% among citizens in Slovenia [24], 55.3\% and 55\% among medical students in Pakistan [25] and Egypt [26] respectively, 56.9\% among medical undergraduate students in Nigeria [27], and $80.9 \%$ among female university students in Malaysia [28]. The major influential reason behind the higher propensity of self-medication might be the unregulated easy availability of all categories of medicine without prescription.

Similar to some previously published articles [22,29-31], headache, common cold, fever, pain, and vomiting were the most common symptoms for self-administration of medications mentioned by the respondents. It was quoted in our research report that the most common cause for self-treatment with drugs was the insignificance of the illness which did not require a doctor's visit. Similar outcomes were reported by the study conducted in India [7,32]. This type of attitude of the respondents may be attributed to a disregard and absence of consciousness about the advancement of diseases. Sometimes the people who practice medication for self-treatment may suffer from a serious illness as the symptoms of many diseases are primarily mild but wrong diagnosis and treatment may promote serious health hazards. However, in agreement with other studies, easy availability of medicines [4,6], quick relief [16], and time saving [33] were found to be the other causatives for preferring self-medication practice.

As stated earlier, antipyretics, analgesics, antacids, and antidiarrheal drugs were the most common classes of drugs self-prescribed for treatment by almost all of the respondents in our study. Almost identical observations were found in the studies conducted in India [4,34], Pakistan [32], Iran [35], and Ethiopia [8] where these common classes of drugs were frequently used by medical students. Meanwhile, the use of antibiotics was different to that of analgesics and antipyretics. This tendency is because of the knowledge of pharmacy graduates on the resistance and side effects of antibiotics. It is well known that proper medicinal knowledge can promote a good prescribing pattern of pharmacists. However, at the same time inappropriate or irrational use of these drugs can lead to various hazardous effects including the reduction in the capability of microbial flora to resist detrimental microorganisms, the development of multidrug resistance, addiction, toxicity, and other related syndromes [32]. Therefore, such kind of practice should be discouraged.

Our study found that the key factor for self-medication practice by the participants was their adequate pharmacological knowledge which they had gathered from their academic courses. These findings are similar to those from studies conducted in Nepal [7], India [4,33], Malaysia [36], Ethiopia [8], and Pakistan [32]. The second major source of information on self-prescribed drugs was from previous prescriptions for the same illness and this result was analogous to the findings of the study conducted in India [4,33]. Further, other researches conveyed in India [34] and Ethiopia [8] reported the internet as another common source of knowledge on self-prescribed medicines which was the third common source of information in our study results. 
The fact that majority $(52.80 \%)$ of the respondents gathered information about self-medication from the previously prescribed medicines of physicians was consistent with the research work conducted earlier [37]. However as the respondents were younger, they were also influenced by other sources like previous illness experiences, opinions of family members, friends and local people, and advertisement. This result resembles formerly conducted research findings [23,37]. All the students irrespective of the year of the study reported that they were completely aware of the treatment procedure using self-medication. They were also cautious about completing the dose of the medicine, checking the instructions given on the insert before using and also looking for the expiry date of the drug before using it. Less awareness was noted among 1st year students which was similar to the findings of Kalyan et al. [38] and Sontakke et al. [34] Non-inclusion of pharmacology as a subject in the 1st year curriculum could be the reason.

In this research work, about $73.2 \%$ of the respondents believed the practice of self-medication to be part of their own health-care and the proportion was higher than the reports from India [34], Ethiopia [22], and Pakistan [25]. Self-medication can only be considered a part of self-care if legitimate use of medicaments can be ensured. It may lead to accidental drug toxicity as there is always a risk of using expired drugs and also sharing with friends or taking medicines that have been actually prescribed for other problems $[4,29,32,39]$.

\section{Limitations}

The study had some limitations as we faced some complications during the survey. First, we covered only five universities due to shortage of time for the research work. If we had conducted the study in more universities we would have got a more extensive scenario on the self-medication practice among the university students of Bangladesh. Second, many students were busy with their examinations, and lab work for training purposes; so collecting data from them was slightly difficult. Third, students of 1st year and 2nd year were less familiar with some terminologies and complication were created during the understanding of the questionnaire. They had to be given extra explanation. Finally, social desirability bias may have impacted the responses since the interviews were done in person Also the survey did not distinguish between the uses of OTC drugs in self-medication vs. prescription drugs such as antibiotics and may have resulted in confusion among respondents. The survey was not revalidated after translation and may have resulted in some changes in the survey items.

\section{Conclusions}

This descriptive study has demonstrated that self-practice of medication is very common among undergraduate pharmacy students of five renowned universities which was facilitated by the easy availability of drugs and information from previous prescriptions. The use of antibiotics, antidepressants, and sedative among a small segment of students without proper follow up or lab tests by healthcare providers may lead to serious health hazards, not only to the students themselves but also to those to whom they suggest the medication. Therefore, it is the sole responsibility of the health care professionals and drug regulatory authorities to ensure the safe use of drugs and control the exercise of self-administration of medications by describing the total impact of the drugs on the body to the students. As the study was confined to the pharmacy student population, further research is needed to test the prevalence of self-medication practices among the general population and how these differ by type of medication. Furthermore steps should be taken to monitor the drug selling system by stake holders especially of those drugs with potentially harmful effects.

Acknowledgments: The authors are thankful to the management and students of participated institutions for their cordial help. Authors also would like to thank all the volunteer students of the Department of Pharmacy of Noakhali Science and Technology University for their warm support for this research work.

Author Contributions: Md. Omar Reza Seam and Bijoy Laxmi Saha carried out the data collection process and conducted the research work. Bijoy Laxmi Saha wrote the manuscript. Palash Karmakar, M. Shahabuddin Kabir Choudhuri, Mohammad Mafruhi Sattar, and Abhijit Das carried out conception and design of the study, statistical analysis, and 
interpretation of data. Rita Bhatta, Md. Monir Hossain and S. M. Naim Uddin helped in the data collection procedure, revised the manuscript, and gave guidance to improve the quality of the final manuscript. All authors read and approved the final manuscript.

Conflicts of Interest: The author reports no conflict of interests in this work.

\section{References}

1. Ruiz, M.E. Risks of self-medication practices. Curr. Drug Saf. 2010, 5, 315-323. [CrossRef] [PubMed]

2. Bennadi, D. Self-medication: A current challenge. J. Basic Clin. Pharm. 2013, 5, 19-23. [CrossRef] [PubMed]

3. Hernandez-Juyol, M.; Job-Quesada, J.R. Dentistry and self-medication: A current challenge. Med. Oral 2002, 7, 344-347. [PubMed]

4. Kumar, N.; Kanchan, T.; Unnikrishnan, B.; Rekha, T.; Mithra, P.; Kulkarni, V.; Papanna, M.K.; Holla, R.; Uppal, S. Perceptions and practices of self-medication among medical students in coastal South India. PLOS ONE 2013, 8, e72247. [CrossRef] [PubMed]

5. Klemenc-Ketis, Z.; Hladnik, Z.; Kersnik, J. A cross sectional study of sex differences in self-medication practices among university students in Slovenia. Coll. Antropol. 2011, 35, 329-334. [PubMed]

6. Kumari, R.; Kiran, K.D.; Bahl, R.; Gupta, R. Study of knowledge and practices of self-medication among medical students at Jammu. J. Med. Sci. 2012, 15, 141-144.

7. Mehta, R.K.; Sharma, S. Knowledge, attitude and perception of self-medication among medical students. IOSR J. Nurs. Health Sci. 2015, 4, 89-96.

8. Afolabi, A.O. Factors influencing the pattern of self-medication in an adult Nigerian population. Ann. Afr. Med. 2008, 7, 120-127. [CrossRef] [PubMed]

9. Harris, K.M.; Edlund, M.J. Self-medication of mental health problems: New evidence from a national survey. Health Serv. Res. 2005, 40, 117-134. [CrossRef] [PubMed]

10. Angeles-Chimal, P.; Medina-Flores, M.L.; Molina-Rodriguez, J.F. Self-medication in a urban population of Cuernavaca, Morelos. Salud Publ. Mex. 1992, 34, 554-561.

11. Figueiras, A.; Caamano, F.; Gestal-Otero, J.J. Sociodemographic factors related to self-medication in Spain. Eur. J. Epidemiol. 2000, 16, 19-26. [CrossRef] [PubMed]

12. Hayran, O.; Karavus, M.; Aksayan, S. Help-seeking behavior and self-medication of a population in an urban area in Turkey: Cross sectional study. Croat. Med. J. 2000, 41, 327-332. [PubMed]

13. Martins, A.P.; Miranda, A.C.; Mendes, Z.; Soares, M.A.; Ferreira, P.; Nogueira, A. Self-medication in a Portuguese urban population: A prevalence study. Pharmacoepidemiol. Drug Saf. 2002, 11, 409-414. [CrossRef] [PubMed]

14. Chang, F.R.; Trivedi, P.K. Economics of self-medication: Theory and evidence. Health Econ. 2003, 12, 721-739. [CrossRef] [PubMed]

15. Alam, N.; Saffoon, N.; Uddin, R. Self-medication among medical and pharmacy students in Bangladesh. BMC Res. Notes 2015, 8, 763. [CrossRef] [PubMed]

16. Sawalha, A.F. Assessment of self-medication practice among university students in Palestine: Therapeutic and toxicity implications. IUG J. Nat. Stud. 2015, 15, 267-282.

17. Kiyingi, K.; Lauwo, J. Drugs in the home: Danger and waste. World Health Forum 1992, 14, 381-384.

18. Loyola Filho, A.I.; Lima-Costa, M.F.; Uchoa, E. Bambui project: A qualitative approach to self-medication. Cad. Saude Publ. 2004, 20, 1661-1669. [CrossRef]

19. Mumtaz, Y.; Jahangeer, S.; Mujtaba, T.; Zafar, S.; Adnan, S. Self-medication among university students of Karachi. J. Liaquat Univ. Med. Health Sci. 2011, 10, 102-105.

20. Castel, J.M.; Laporte, J.R.; Reggi, V.; Aguirre, J.; Buschiazzo, P.M.; Coelho, H.L.; Batista, M.D.C.D.; Carvalho, M.L.; Righi, R.E.; Prieto, J.C.; et al. Multicenter study on self-medication and self-prescription in six Latin American countries. Clin. Pharmacol. Ther. 1997, 61, 488-493. [CrossRef]

21. Babu, M.M. Factors contributing to the purchase of over the counter (OTC) drugs in Bangladesh: An empirical study. Int. J. Third World Med. 2008, 6, 9-24.

22. Abay, S.M.; Amelo, W. Assessment of self-medication practices among medical, pharmacy, and health science students in Gondar university, Ethiopia. J. Young Pharm. 2010, 2, 306-310. [CrossRef] [PubMed]

23. Gutema, G.B.; Gadisa, D.A.; Kidanemariam, Z.A.; Berhe, D.F.; Berhe, A.H.; Hadera, M.G.; Hailu, G.S.; Abrha, N.G.; Yarlagadda, R.; Dagne, A.W. Self-medication practices among health sciences students: The case of Mekelle university. J. Appl. Pharm. Sci. 2011, 1, 183-189. 
24. Smogavec, M.; Softic, N.; Kersnik, J.; Klemenc-Ketis, Z. An overview of self-treatment and selfmedication practices among Slovenian citizens. Zdr. Vestnik 2010, 79, 757-763.

25. Zafar, S.N.; Syed, R.; Waqar, S.; Irani, F.A.; Saleem, S. Prescription of medicines by medical students of Karachi, Pakistan: A cross-sectional study. BMC Public Health 2008, 8, 162. [CrossRef] [PubMed]

26. El Ezz, N.; Ez-Elarab, H. Knowledge, attitude and practice of medical students towards self-medication at Ain Shams university, Egypt. J. Prev. Med. Hyg. 2011, 52. [CrossRef]

27. Fadare, J.O.; Tamuno, I. Antibiotic self-medication among university medical undergraduates in northern Nigeria. J. Public Health Epidemiol. 2011, 3, 217-220.

28. Ali, S.E.; Ibrahim, M.I.; Palaian, S. Medication storage and self-medication behaviour amongst female students in Malaysia. Pharm. Pract. 2010, 8, 226-232. [CrossRef]

29. Hughes, C.M. Monitoring self-medication. Expert Opin. Drug Saf. 2003, 2, 1-5. [CrossRef] [PubMed]

30. Nandha, R.; Chhabra, M.K. Prevalence and clinical characteristics of headache in dental students of a tertiary care teaching dental hospital in northern India. Int. J. Basic Clin. Pharmacol. 2013, 2, 51-55. [CrossRef]

31. Sarahroodi, S.; Maleki-Jamshid, A.; Sawalha, A.F.; Mikaili, P.; Safaeian, L. Pattern of self-medication with analgesics among Iranian university students in central Iran. J. Family. Community Med. 2012, 19, 125-129. [CrossRef] [PubMed]

32. Hughes, C.M.; McElnay, J.C.; Fleming, G.F. Benefits and risks of self medication. Drug Saf. 2001, 24, $1027-1037$. [CrossRef] [PubMed]

33. Souza, L.A.; da Silva, C.D.; Ferraz, G.C.; Sousa, F.A.; Pereira, L.V. The prevalence and characterization of self-medication for obtaining pain relief among undergraduate nursing students. Rev. Lat. Am. Enfermagem. 2011, 19, 245-251. [CrossRef] [PubMed]

34. Sontakke, S.D.; Bajait, C.S.; Pimpalkhute, S.A.; Jaiswal, K.M.; Jaiswal, S.R. Comparative study of evaluation of self-medication practices in first and third year medical students. Int. J. Biol. Med. Res. 2011, 2, 561-564.

35. Lukovic, J.A.; Miletic, V.; Pekmezovic, T.; Trajkovic, G.; Ratkovic, N.; Aleksic, D.; Grgurevic, A. Self-medication practices and risk factors for self-medication among medical students in Belgrade, Serbia. PLoS ONE 2014, 9, e114644. [CrossRef] [PubMed]

36. Kayalvizhi, S.; Senapathi, R. Evaluation of the perception, attitude and practice of self medication among business students in 3 select cities, south India. IJEIMS 2010, 1, 40-44.

37. Pereira, C.M.; Farias Alves, V.; Freire Gasparetto, P.; Carneiro, D.S.; de Carvalho, D.D.G.R.; Ferreira Valoz, F.E. Self-medication in health students from two Brazilian universities. Rev. Sul-Bras. Odontol. 2012, 9, 361-367.

38. Kalyan, V.S.; Sudhakar, K.; Srinivas, P.; Sudhakar, G.; Pratap, K.; Padma, T.M. Evaluation of self-medication practices among undergraduate dental students of tertiary care teaching dental hospital in south India. J. Educ. Ethics Dent. 2013, 3, 21-25. [CrossRef]

39. Sharif, S.I.; Ibrahim, O.H.M.; Mouslli, L.; Waisi, R. Evaluation of self-medication among pharmacy students. Am. J. Pharmacol. Toxicol. 2012, 7, 135-140. [CrossRef]

(C) 2018 by the authors. Licensee MDPI, Basel, Switzerland. This article is an open access article distributed under the terms and conditions of the Creative Commons Attribution (CC BY) license (http://creativecommons.org/licenses/by/4.0/). 